\title{
ENTREVISTA A LA CONGRESISTA PROPULSORA DEL PROYECTO DE LEY DE FEMINICIDIO EN PERÚ
}

\author{
Luisa Maria Cuculiza Torre
}

1. ¿Cuáles fueron los motivos por los cuales decidió presentar el Proyecto de Ley sobre la implementación del Feminicidio como delito?

La decisión fue tomada porque me cansé de ver tantas muertes de mujeres en manos de "anormales", ya que ahora la mujer muere como si estuviera en un "camal de pollos" y esa situación sigue en aumento. A mí esta ley me ha costado cuatro años de lucha en el Congreso porque el machismo es aún imperante; sin embargo, no me he dado por vencida $y$, finalmente, se pudo regular. Ahora esos "desalmados" van a pensar dos veces antes de atreverse a matar a una mujer.

Sabemos que usted es una ardua defensora de los derechos de las mujeres, de qué manera cree que se reivindicarán sus derechos tras la promulgación de la Ley sobre el Feminicidio

La mejor forma de que los derechos de las mujeres sean reivindicados es con la aplicación de esta Ley en la realidad; es decir, que no se quede simplemente en el papel, sino que los jueces la apliquen a los criminales que asesinan a las mujeres y que a esos criminales les caiga todo el peso de la ley para que de esa forma, haya una mayor conciencia en los hombres que violentan a las mujeres y que la piensen dos veces antes de hacerlo.

Por otro lado, hay que recordar que el Perú es el primer país de Sudamérica en cuanto a muerte de mujeres a manos de su pareja y lamentablemente es un fenómeno que está en aumento por eso yo celebro que la ley haya sido aprobada, pero también debe ser aplicada y de eso se encarga el Poder Judicial.

Tampoco puede ser posible que las cifras de feminicidio hayan aumentado tanto en tan poco tiempo, pues cuando fui Ministra de la Mujer durante los años 1999 y 2000 morían de 5 a 6 mujeres al mes, mientras que actualmente mueren de 12 a 14 mujeres al mes, tenemos que parar con esta situación de una vez por todas. 
3. En su opinión, ¿cuál cree que sea el factor desencadenante que lleva a una mujer de estar en una situación de violencia familiar a ser víctima de un Feminicidio por parte de su pareja?

Generalmente, las mujeres en situación de violencia familiar provienen de familias violentas y no se sabe muy bien la razón, probablemente por una psicológica, buscan parejas agresivas, extremadamente agresivas; que empiezan jaloneándolas, luego pateándolas y finalmente terminan matándolas. Estas mujeres soportan toda clase de violencia porque no son independientes económicamente, hoy en día en el siglo XXI debe ser inconcebible que una mujer sea dependiente de su marido, ellas tienen que hacerse cargo de ellas mismas para que apenas perciban cuotas de violencia por parte de sus parejas puedan dejarlos. En esta línea a mi me indigna que muchas de ellas lleguen a soportar tanta violencia. A mi despacho y a la Comisión de la Mujer y Familia llegan muchos casos de violencia familiar, yo las ayudo, veo para que tengan abogados y pongan sus denuncias; y me da mucha cólera que tiempo después cuando les hago seguimiento a sus casos me entere que han retirado las denuncias. Es una situación que debe revertirse.

4. ¿Cuál es la responsabilidad de la sociedad peruana y el Estado para que desaparezcan estos crímenes producto de la misoginia y discriminación contra la mujer? Por otro lado, ¿cuáles son las medidas a tomar por el Estado y ciudadanía en general con el fin de romper con el círculo de violencia contra las mujeres?

La sociedad peruana es la principal responsable de que tantos casos de feminicidio se presenten, es una sociedad machista que recién en los últimos tiempos se está preocupando realmente por la situación de la mujer. El Estado peruano, tiene que otorgar un mayor presupuesto para que se puedan crear casas de refugios, para que se puedan implementar más comisarías de la mujer y sobre todo para que se realicen campañas que incentiven la igualdad de género, dándole especial énfasis a los colegios puesto que los niños y niñas son los que tienen que empezar a tomar conciencia de la igualdad de género.

5. Como estudiantes de Derecho sabemos que la incorporación del feminicidio a la legislación nacional regulará solo parte de la situación de violencia extrema que vive un sector de la población femenina en su relación de pareja; como parlamentaria que propuestas plantearía al ejecutivo, en específico al Ministerio de la Mujer y Poblaciones Vulnerables, para que este escenario se revierta desde raíz.

Considero que es un trabajo en conjunto entre el Ministerio de la Mujer y Poblaciones Vulnerables y el Ministerio de Educación, pienso que la mejor forma de acabar con la violencia contra la mujer es erradicarla desde raíz y esto solo se conseguirá si educamos adecuadamente a nuestros niños y les hacemos entender de que la violencia no es normal para que no lo repitan en un futuro. Debemos enseñarles que todos somos iguales y que la violencia bajo ningún motivo está justificada, pero para ello se necesita un trabajo combinado entre ambos ministerios, pues si no se toman cartas en el asunto, a largo plazo toda esta situación se va a convertir en una tragedia. 
Proyecto de Ley de feminidio en Perú

ya que los niños que han sufrido y vivido la violencia hacia ellos o han sido testigos de la violencia contra sus madres van a crecer como seres anormales, pues es muy difícil hacer entender a un niño de que la violencia no es normal, cuando este ya se ha acostumbrado que su padre maltrate constantemente a su madre y de alguna manera esto se va normalizando mientras que el niño crece y repetirá la misma historia más adelante.

6.

Habiendo sido la Ley del feminicidio publicada en el Diario Oficial El

Peruano el 27 de diciembre de 2011, ¿cuáles cree que deben ser las estrategias a implementar por el estado a fin de que esta norma y otras relacionadas a la violencia contra la mujer causen impacto en los imaginarios colectivos?

Como mencioné anteriormente dando un mayor presupuesto para la causa, se necesita la implementación de muchos lugares como comisarías y centros de ayuda para que esta situación se pueda revertir. Pero sobre todo se tiene que cumplir la norma, desde su publicación se han presentado 15 homicidios de mujeres pero solo 2 de ellos han sido catalogados como Feminicidios, por lo que también hay que actualizar y capacitar a los Fiscales y Jueces para que respeten esta nueva figura penal.

Vuelvo a repetir, si bien la Ley de feminicidio es un gran avance para frenar la violencia contra las mujeres, no debemos permitir de que esta se quede en el papel, sino se deben realizar trabajos conjuntos que se traduzcan en capacitaciones a operadores de justicia, educación en igualdad de género a los niños y creación de establecimientos públicos en los que las mujeres víctimas de violencia puedan acudir y hacer valer sus derechos. 